\title{
Prevalence of canine parvovirus infection in South Eastern region, Nigeria
}

\author{
C. S. Ukwueze ${ }^{*}$, B. M. Anene ${ }^{2}$, R. C. Ezeokonkwo ${ }^{3}$ and C. I. Nwosuh ${ }^{4}$ \\ ${ }^{1}$ Department of Veterinary Medicine, Michael Okpara University of Agriculture, Umudike, Nigeria. \\ ${ }^{2}$ Department of Veterinary Medicine, University of Nigeria, Nsukka, Nigeria. \\ ${ }^{3}$ Department of Veterinary Parasitology, University of Nigeria, Nsukka, Nigeria. \\ ${ }^{4}$ Research Directorate, National Veterinary Research Institute, Vom, Nigeria.
}

\begin{abstract}
\section{Background}

The study on Canine Parvovirus type 2 (CPV-2) infection was carried out in South Eastern Nigeria using Immunochromatographic (IC) test.
\end{abstract}

\section{Methods}

Three states namely Enugu, Abia and Anambra were randomly selected for the study, using simple random sampling method. Six major Veterinary clinics and six kennels (two per state) were also selected by purposive sampling method. The risk factors considered in this study were; age, breed, sex, vaccination status and location. A total of $300 \mathrm{dogs}$ were sampled using purposive sampling method, to select suspected cases of CPV-2 (diarrhoeic) and exposed dogs.

\section{Results}

The survey showed overall prevalence of $37.3 \%$ among the dogs studied in the area. There was no association between the occurrence of CPV-2 and location, sex and vaccination status. According to location the prevalence, was $43 \%, 38 \%$ and $31 \%$ in Enugu, Abia and Anambra states, respectively ( $>0.05$ ). Sex-related prevalence was $38.0 \%$ and $36.6 \%$ for male and female, respectively ( $p>0.05)$. According to vaccination status, the prevalence was, $36.8 \%, 34.0 \%$, and $48.7 \%$ for vaccinated, unvaccinated and incomplete vaccinated dogs, respectively $(\mathrm{p}>0.05)$. The result of the survey showed association $(\mathrm{p}<0.05)$ with the occurrence of CPV-2 and age, breed and mortality rates. According to age, the prevalence was, $42.9 \%, 30.6 \%$, and $17.0 \%$ for $0-6$ months, 7-12 months and one year and above, respectively $(\mathrm{p}<0.05)$. Breed-related prevalence showed Rottweiler (63.4\%), Pit bull (50.0\%), Toy breeds (50.0\%), Great dane (40.0\%), Bull mastiff $(39.4 \%)$, Alsatian (36.0\%), Boerboel (36.0\%), Caucasian (35.8\%) and Mongrel $(11.1 \%)$ respectively, $(\mathrm{p}<0.05)$. Case mortality rate of $72 \%$ was also recorded.

\section{Conclusions}

This study showed, that canine parvovirus is endemic in study area and most prevalent in dogs less than six months of age.

Key words: Prevalence, CPV-2, IC test, Dogs, Veterinary clinics, South Eastern Nigeria

*Correspondence: chynet2006@yahoo.com

All right reserved 0424/2018

Copyright (C) 2018 Bangladesh Society for Veterinary Medicine. This is an open access article under the CC BY license (http://creativecommons.org/licenses/by/4.0/), which permits unrestricted use, distribution, and reproduction in any medium, provided the original author and source are credited. 


\section{Introduction}

Canine Parvovirus (CPV-2) has become an important problem to dog population worldwide. In Nigeria, canine parvoviral enteritis is now a regular occurrence, has been associated largely with frequent cause of morbidity and mortality of dogs, particularly in puppies younger than six months of age (Goddard and Leisewitz, 2010; Shima et al., 2015). The virus is transmitted via the faeco-oral route and preferentially infects rapidly dividing cells, showing a tropism for small intestinal epithelium, lymphoid tissue, bone marrow, and occasionally the myocardium if the puppy is less than three weeks of age (Prittie, 2004). Estimated case fatality rates have varied between studies, but mostly range between 25 and 35\% (Brinke and Neiger, 2010; Kalli et al., 2010). In the absence of treatment, case fatality rates approach $91 \%$; however, with prompt and aggressive treatment, survival rates can reach 80 to $95 \%$ (Prittie, 2004). Experiences have shown that morbidity and mortality rates of canine parvoviral enteritis vary and are dependent on the immune status, age, sex breed (Nelson and Couto, 1998; Foster and Smith, 2011), seasonal variation, geographical distributions (Houston et al., 1996; Mohammed et al., 2005) and how early treatment is instituted (Otto et al., 1997).

The most commonly reported risk factors predisposing dogs to CPV-2 infection is lack of protective immunity. This may be due to failure of passive transfer of antibodies via colostrum, incomplete or ineffective primary vaccination course, or failure of vaccination to induce immunity because of interference by maternal antibodies (Smith-Carr et al., 1997). Although the prevalence of CPV-2 has been reported in some states in Nigeria (Mohammed et al., 2005; Adejumobi et al., 2017), comparative data of the prevalence and the risk factors of CPV-2 in states in South Eastern region of Nigeria is dearth in available literature. The findings of the present study will be useful to clinicians, researchers and even dog owners in the study area in decision making with regards to canine parvoviral enteritis. It is also expected to serve as a useful tool to the government and other policy makers on measures to modify the control of the virus based on its endemicity in this part of the country. This survey was therefore conducted to determine the prevalence and risk factors associated with canine parvovirus in dogs presented to Veterinary Clinics and kennels in South Eastern region, Nigeria.

\section{Materials and Methods}

\section{Study area}

This study was carried out in three states in South Eastern Nigeria namely; Abia, Anambra and Enugu States. Abia State is located on latitude 4$6^{\circ} \mathrm{N}$, longitude $7-8^{\circ} \mathrm{E}$ and altitude $244-305 \mathrm{~m}$ (highest point) above sea level. It occupies a total land area of $6,320 \mathrm{Km}^{2}$. Anambra State is located between latitude $6^{\circ} 20 \mathrm{~N}$ and longitude $7^{\circ} 00 \mathrm{E}$. It occupies the land area of about $4,844 \mathrm{~km}^{2}$. Enugu State is located between latitude $5{ }^{\circ} 55 \mathrm{~N}$ and $7^{\circ} 55 \mathrm{~N}$ and longitude $6^{\circ} 53 \mathrm{E}$ and $7^{\circ} 55 \mathrm{E}$. It occupies a total land area of about $7,161 \mathrm{Km}^{2}$.

\section{Sampling technique}

Simple random sampling method was used to select three states (Abia, Anambra and Enugu) out of five states in South Eastern Nigeria. Six major veterinary clinics and six kennels (two per state) were selected by purposive sampling method. The risk factors considered in this study were; age, breed, sex, vaccination status and location. Purposive sampling method was used to select suspected cases of CPV-2 (animals with diarrhoea and vomiting), dogs that had contact with infected dogs and kennels with history of CPV-2. Scheduled visits were made to the purposively selected Veterinary Clinics and Kennels (once a week) throughout the period of study. The required sample size was determined as described by Thrusfield, (2005).

\section{Sample collection}

A total of 300 dogs were sampled using Immunochromatographic (IC) test, with a commercial rapid CPV-2 Antigen test kit (J \& G Biotech Ltd. UK), following the manufacturer's instructions. This kit is a chromatographic immunoassay for the qualitative detection of parvovirus antigen in canine faeces.

Briefly, faecal swabs were collected from the rectum or from freshly voided faeces and mixed with the assay diluents. The mixture was stirred evenly, and four (4) drops of supernatant were added into the sample hole of the IC test device. The test result was interpreted after 5-10 minutes. 


\section{Prevalence of canine parvovirus infection in South Eastern region, Nigeria}

A colour band which appears in the left section of the result window shows that the test is working properly, which is the control band. The right section of the result window indicates the test results. If another colour band appears in the right section of the result window, this band is the test band. The presence of only one band within the result window indicates a negative result. The presence of two colour bands ( $\mathrm{T}$ and $\mathrm{C}$ ) within the result window, no matter which band appears first, indicates a positive result. If the purple colour band is not visible within the result window after performing the test, the result is considered invalid (Esfandiari and Klingeborn, 2000).

\section{Statistical Analysis}

Data obtained were analyzed using Chi-square test and $\mathrm{p}$ values < 0.05 were considered statistically significant. Descriptive statistics were used to obtain the different frequencies of the variables.

\section{Results}

The overall prevalence of CPV-2 in the study area was $37.3 \%$, and there was no association $(\mathrm{P}>0.05)$ between the occurrence of CPV-2 and location, sex and vaccination status. The prevalence according to location were $43 \%, 38 \%$ and $31 \%$ in Enugu, Abia and Anambra States, respectively, $\chi^{2}$ value $=3.106, \mathrm{df}=2, \mathrm{P}$ value $=$ 0.212 (Figure. 1), Sex-related prevalence were $38.0 \%$ and $36.6 \%$ for male and female, respectively, $\chi^{2}$ value $=0.058, \mathrm{df}=1, \mathrm{P}$ value $=$ 0.809 (Figure. 2). The prevalence according to vaccination status were, $36.8 \%, 34.0 \%$, and $48.7 \%$ for vaccinated, unvaccinated and incomplete vaccinated $\operatorname{dogs}$, respectively, $\chi^{2}$ value $=2.711, \mathrm{df}=2, \mathrm{P}$ value $=0.258$ (Figure. 3 ).

However, there was a strong association between the occurrence of CPV-2 and age, breed and case mortality rates $(\mathrm{P}<0.05)$. Prevalence according to age were, $42.9 \%, 30.6 \%$, and $17.0 \%$ for $0-6$ months, 7-12 months and one year and above, respectively $\chi^{2}$ value $=11.825, \mathrm{df}=2, \mathrm{P}$ value $=$ 0.003 (Figure. 4). Breed-related prevalence showed Rottweiler 26/41 (63.4\%), Pit bull $1 / 2$ (50.0\%), Toy breeds $2 / 4(50.0 \%)$, Great dane $2 / 5$ (40.0\%), Bull mastiff 13/33 (39.4\%), German shepherd 35/98 (36.0\%), Boerboel 10/28 (36.0\%), Caucasian 19/35 (35.8\%) and Mongrel $4 / 36(11.1 \%)$ respectively, $\chi^{2}$ value $=23.179, \mathrm{df}$ $=8, \mathrm{P}$ value $=0.003$ (Figure. 5). Case mortality rate of $72.0 \%$ and survival rate of $28.0 \%$ were also recorded (Figure. 6).

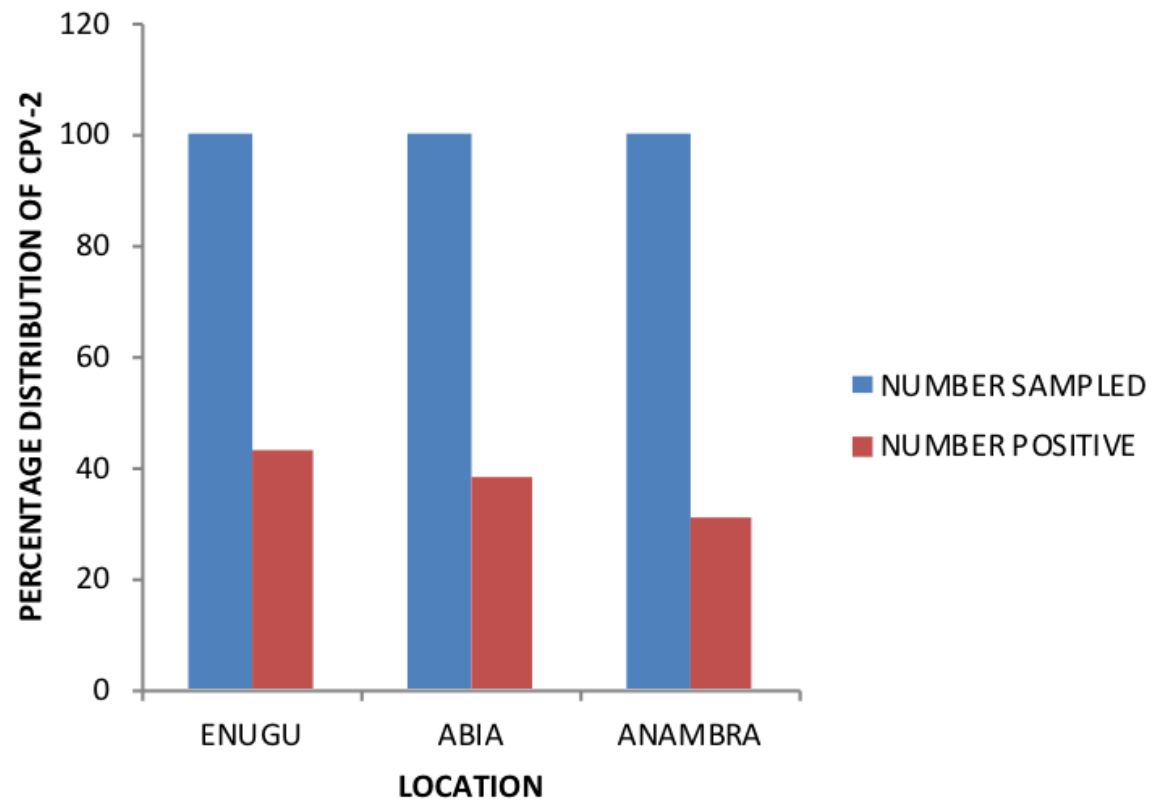

Figure 1: Distribution of CPV-2 in dogs in South Eastern Nigeria 


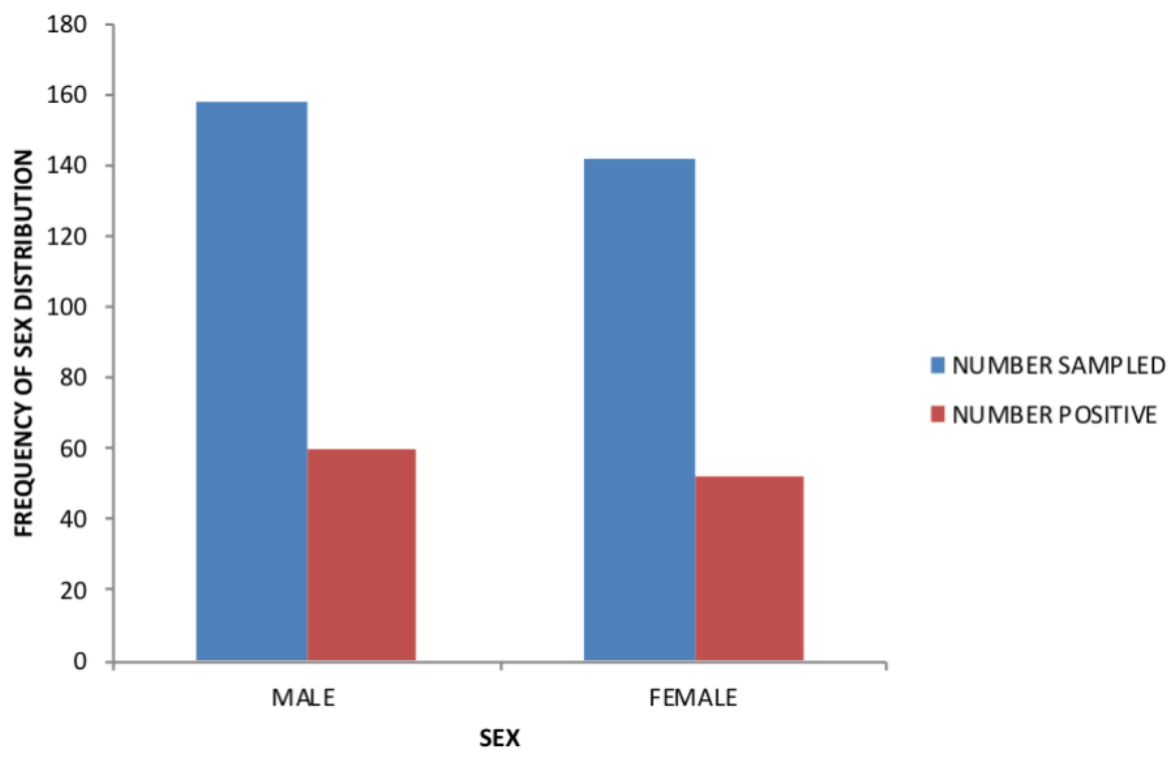

Figure 2: Sex distribution of CPV-2 in dogs in South Eastern Nigeria

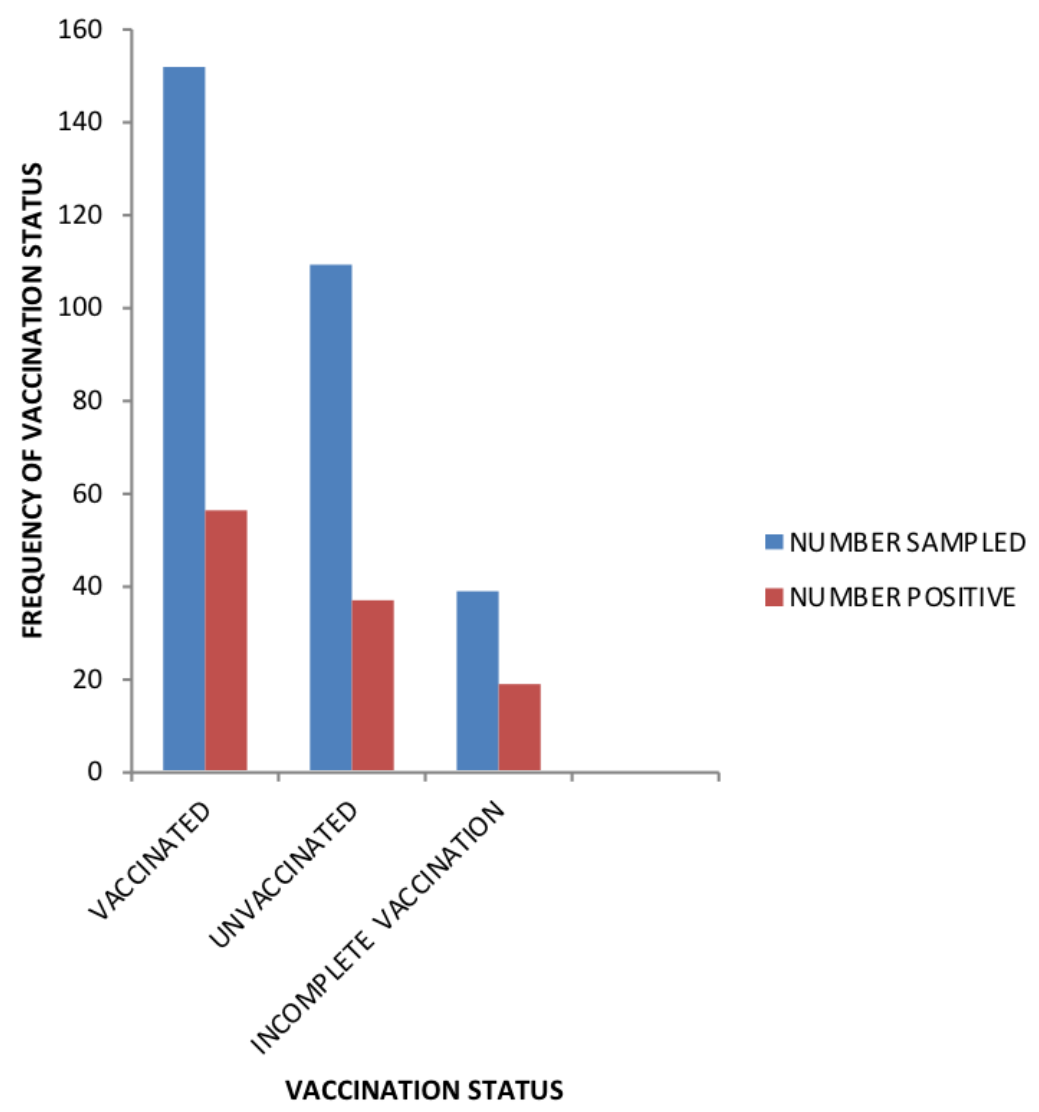

Figure 3: Vaccination status of dogs infected with CPV-2 in South Eastern Nigeria 
Prevalence of canine parvovirus infection in South Eastern region, Nigeria

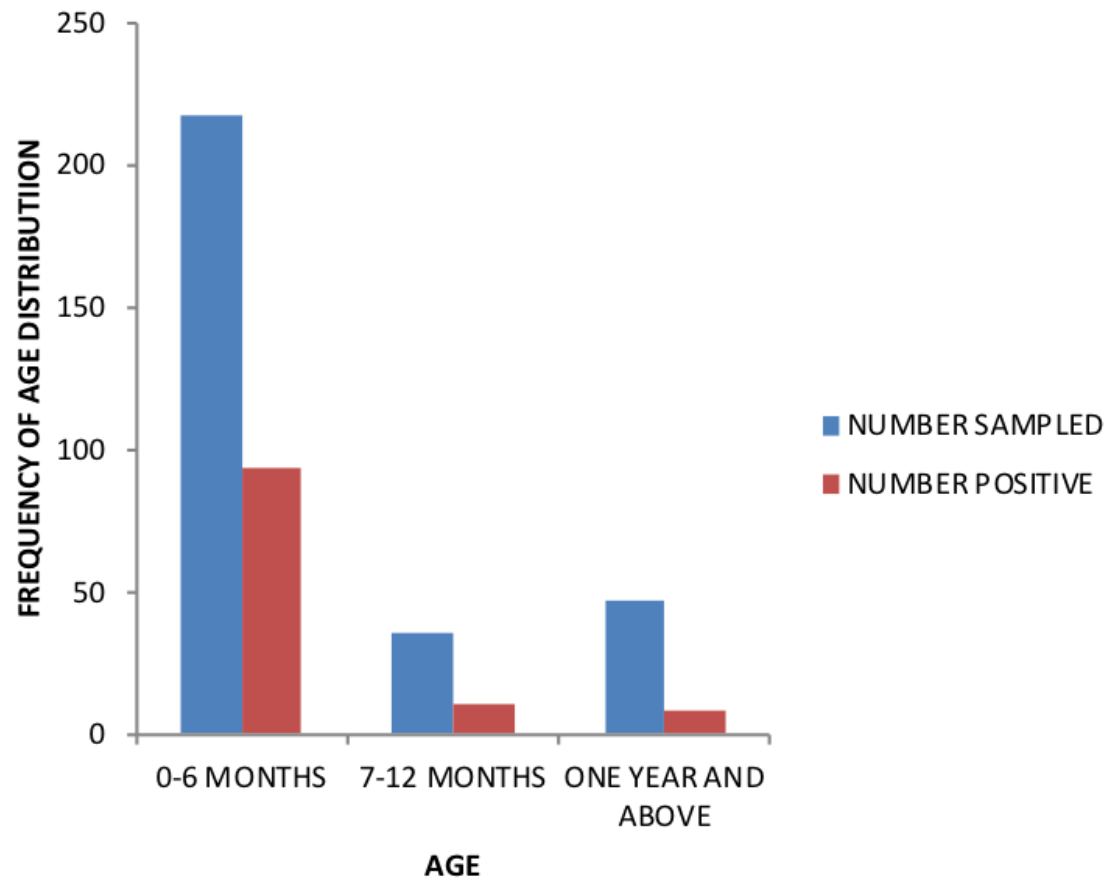

Figure 4: Age distribution of CPV-2 in dogs in South Eastern Nigeria

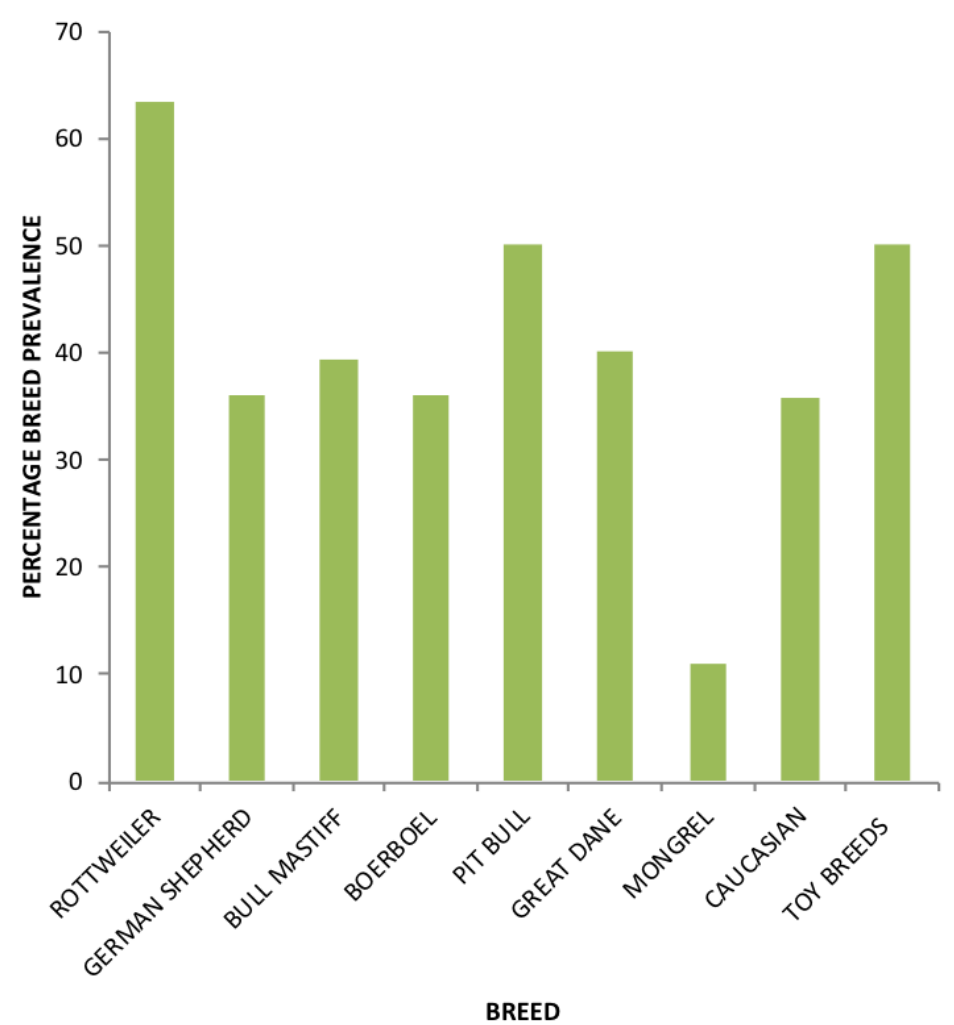

Figure 5: Breed distribution of CPV-2 in dogs in South Eastern Nigeria 


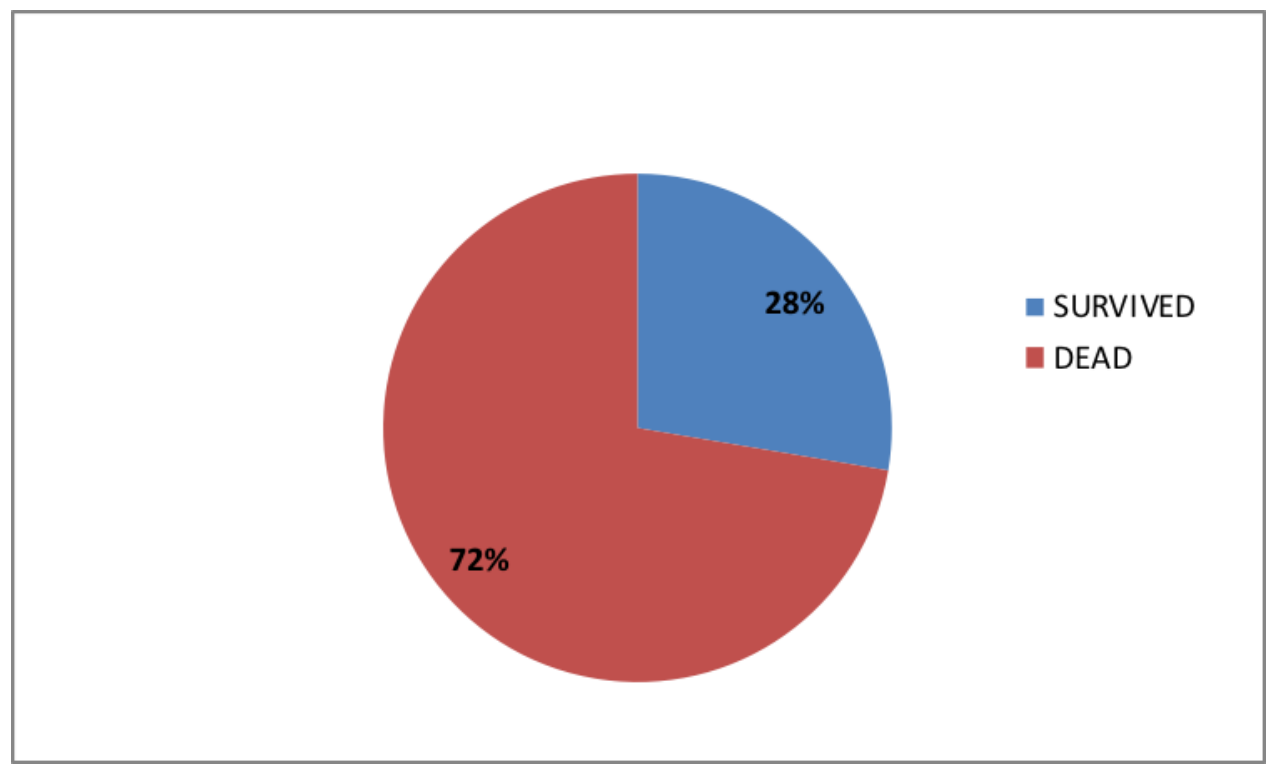

Figure 6: Proportion of dogs that died due to CPV-2 in South Eastern Nigeria.

\section{Discussion}

The results of this study, confirmed the endemicity of canine parvovirus in South Eastern region of Nigeria, with the overall prevalence of $37.7 \%$ among the sampled dog population. This result agrees with the finding of Greene and Decaro (2012) who stated that canine parvoviral enteritis is one of the most common infectious diseases of dogs and the most prevalent virus in dogs with infectious diarrhoea. A lower prevalence of $17.14 \%$ was, however obtained in similar study in Jos, Plateau State, Nigeria (Ogbu et al., 2016). Location did not statistically affect the distribution of CPV-2 in dogs in South Eastern Nigeria. This result is in accordance with the report of Truyen (2006) who stated that distribution of canine parvovirus infection is worldwide. CPV-2 is ubiquitous and can survive in the environment for more than a year, enabling the exposure of susceptible dogs to infected faeces, vomitus or fomites (Sykes, 2014). The virus is also extremely resistant to temperature changes and commonly used disinfectants (Decaro and Buonavogila, 2012).

The results revealed that sex had no influence on the occurrence of CPV-2 in dogs. This result agrees with the findings of other workers such as
Castro et al., 2007 and Gombac et al., 2008a, who stated that all sexes of dogs have been found to be susceptible to parvovirus infection. It however, contradicts Gombac et al. (2008b) on a study in Slovenia which showed that significantly more male dogs $(83.3 \%)$ died due to canine parvovirus infection than females (16.7\%). In this study, we also observed, that vaccination did not influence the distribution of CPV-2 in the study area. The result, agrees with Kingborg et al. (2002), who stated that some vaccinated dogs still contract canine parvovirus, although it is more likely a failure of the immune system to respond than a problem with the vaccine itself. However, vaccine failure can also occur, due to poor vaccine quality, irregular or incomplete vaccination programme, lack of maintenance of cold chain and poor storage of vaccine as a result of erratic power supply. This result could also be attributed to antigenic variations and genetic mutation of CPV-2 in the amino acid sequence, which has been reported by several researchers (Decaro et al., 2008; Decaro et al., 2009; Nandi and Kumar, 2010), and these mutants are yet to be incorporated in the vaccines used in the field.

From this study, age showed significant influence on the occurrence of CPV-2 in dogs in the study 
area. The prevalence was highest in dogs between 0-6 months of age, followed by 7-12 months of age and least in adult dogs (> one year). This result is in accordance with the findings of Ettinger and Feildman (1995) and Greene and Decaro (2012) who stated that puppies are more prone to canine parvovirus than adult dogs. Adults are thought to be more resistant to CPV-2 infection due to the age-reduced susceptibility and presence of specific immunity induced by vaccination or previous (often subclinical) infections. Infections in puppies occur mainly between 4-12 weeks, in concomitance with when the maternal antibodies (MDA) begin to wane (Greene and Decaro, 2012). Adejumobi et al. (2017) in a similar study observed a higher prevalence of $80 \%$ in dogs less than one year, $10 \%$ in adult dogs and $10 \%$ in dogs whose ages were unidentified.

In the present study, the breeds of dogs sampled also influenced the occurrence, of canine parvovirus. Among the common (exotic) breeds within the study area, Rottweiler, Bull mastiff, Alsatian, Boerboel and Caucasian had the highest prevalence, compared to the Nigerian local breed (Mongrel) which had the lowest prevalence. This finding is consistent with the reports of Gombac et al. (2008a) and Ling et al. (2012) that German shepherd, Doberman pinscher and Rottweiler are at high risk of developing canine parvoviral enteritis. The high prevalence found in Pit bull, Great dane and Toy breeds in this study may be attributed to the fewer number of the dog breeds sampled. Greene and Decaro, (2012) also reported that Rottweiler, Doberman Pinschers, Labrador retrievers, American Staffordshire terriers, German shepherds and Alaskan sled dogs had higher risk of CPV infection. This study also agrees with (Houston et al., 1996; Ling et al., 2012) who reported that exotic breeds of dogs appear to be at greater risk of developing parvoviral enteritis than local breeds.

From this study, the dogs that were diagnosed of canine parvovirus had a significantly high mortality rate. This result corroborates most recent findings (Kalli et al., 2010; Mylonakis et al., 2016), which stated that CPV-2 is among the most killer, diseases of puppies and unvaccinated dogs. The primary goal of treatment of CPV2 will include restoration of fluid and electrolyte balance and preventing secondary bacterial infection (Greene and Decaro, 2012). So, the high mortality rate, in this study may also be attributed to lack of commitment on the part, of dog owners, who always patronize quacks and fail to present their dogs for routine veterinary care.

\section{Conclusions}

It was concluded from the study, that CPV-2 infects dogs, mainly puppies less than six months of age in South Eastern region of Nigeria. It is speculated that the current vaccines used in the region are of questionable potency or non protective, as most of the infected dogs were duly vaccinated.

\section{Acknowledgment}

The authors are grateful to the following clinicians Dr. Amaka Emewusim, Animal World, Umuahia, Dr. Samuel Chukwu, Jimcare Veterinary Services, Aba, Dr. Chioma Egwogu VTH, MOUAU, Dr. Akpa Everest, Eva Vet, Enugu, Dr. Ikechukwu Udani, VTH, UNN, Dr. Ifeoma Etukokwu, Apex Veterinary Services, Onisha and Dr. Webster Okonwo, Tropical Veterinary Centre, Ekwulobia.

\section{References}

1. Adejumobi OA, Omotosho OO, Omobowale TO, Akinrinmade JF. Retrospective study of the prevalence and pattern of parvoviral enteritis presented at the Veterinary Teaching Hospital, University of Ibadan, Nigeria. European Journal of Pharmaceutical and Medical Research. 2017; 4(03), 109113.

2. Brinke $\mathrm{N}$, Neiger $\mathrm{R}$. The influence of parvovirus infection and other factors on the survival of dogs with haemorrhagic diarrhoea. Kleintierpraxis. 2010; 55, 417422.

3. Castro TX, Miranda SC, Labarthe NV, Silva LE, Cubel Garcia RCN. Clinical and epidemiological aspects of canine parvovirus (CPV) enteritis in the State of 
Rio de Janeiro: 1995-2004. Arquivo Brasileiro de Medicina Veterinária e Zootecnia. 2007; 59 (2): 333-339.

4. Decaro N, Buonavoglia C. Canine Parvoviral Enteritis. In: Gavier-Widen D, Duff JP, Meredith A, editors. Infectious Diseases of Wild Mammals and Birds in Europe. Somerset, New Journal: WileyBlackwell. 2012; PP. 182-184.

5. Decaro N, Cirone F, Desario C, Elia G, Lorusso E, Colaianni ML, Martella V, Buonavoglia C. Severe parvovirus in a 12-yearold $\operatorname{dog}$ that had been repeatedly vaccinated. Veterinary Record. 2009; 164, 593-595.

6. Decaro N, Desario C, Elia G, Martella V, Mari V, Lavazza A, Nardi M, Buonavoglia C. Evidence for immunisation failure in vaccinated adult dogs infected with canine parvovirus type 2c. New Microbiology, 2008; 31, 125-130.

7. Esfandiari J, Klingeborn B. A comparative study of a new rapid and one-step test for the detection of parvovirus in faeces from dogs, cats and mink. Journal of Veterinary Medicine B Infectious Diseases Veterinary Public Health. 2000; 47:145-153.

8. Ettinger SJ, Feildman EC. CPV susceptibility in dogs. Textbook of Veterinary Internal Medicine (4th edition). W. B Saunders Company. 1995; 64-70

9. Foster E, Smith K. Parvovirus: Serious Diarrhoea in Puppies \& Dogs. 2011; www.peteducation.com/article.cfm?c $=2+210$ 2\&aid $=467$

10. Goddard A, Leisewitz, AL. Canine Parvovirus. Veterinary Clinics Small Animal Practice, 2010; 40:1041-1053.

11. Gombac M, Svara T, Tadic M, Pogacnik M. Retrospective study of canine parvovirusis in Slovenia: Case Report. Slovenia Veterinary Research. 2008b; 45(2):73-78.

12. Gombac M, Tadic M, Svara T, Pogacnik M. Study of canine parvovirus in Slovenia. Veterinary Medicine Microbiology. 2008a; 45(3):60-69.

13. Greene CE, Decaro N. Canine Viral Enteritis. In: Greene, C.E. (Ed.),
Infectious Diseases of the Dog and Cat, Fourth edition, Elsevier, 2012; 67-75.

14. Houston DM, Ribble CS, Head LL. Risk factors associated with parvovirus enteritis in dogs: 283 cases (1982-1991). Journal of American Veterinary Medical Association. 1996; 208:542-546.

15. Kalli I, Leontides LS, Mylonakis ME, Adamama- moraitou K, Koutinas AF. Factors affecting the occurrence duration of hospitalization and final outcome in Canine parvovirus infection. Research Veterinary Science. 2010; 89 (2):174-178.

16. Kingborg DJ, Hustead DR, Curry-Galvin EA, Gum B, Henry SC and Bain FT. AVMA Council on biologic and therapeutic agents. Report on cat and dog vaccines. Journal of the America Veterinary Medicine Association. 2002; 221(10):1401-1407.

17. Ling M, Norris JM, Kelman $M$ and Ward MP. Risk factors for death from canine parvoviral-related disease in Australia. Veterinary Microbiology, 2012; 158: 28090.

18. Mohammed JG, Ogbe AO, Zwandor NJ, Umoh JU. Risk factors associated with canine parvovirus enteritis in Vom and Environs. Animal Research International. 2005; 2, 366-368.

19. Mylonakis ME, Kali I, Rallis TS. Canine parvoviral enteritis: update on the clinical diagnosis, treatment, and prevention. Veterinary Medicine: Research and Reports. 2016; 7: 91-100.

20. Nandi S, Kumar M. Canine Parvovirus: current perspective. Indian Journal of Virology. 2010; (21): 31-44.

21. Nelson RW, Couto CG. Small Animal Internal Medicine. 2nd Edition, Mosby, Mary land Heights. 1998.

22. Ogbu KI, Chukwudi IC, Ijomanta OJ, Agwu $\mathrm{EO}$, Chinonye $\mathrm{CN}$. Prevalence of canine parvovirus in Jos North and South Local Government Areas of Plateau State. British Microbiology Research Journal. 2016; 13(2): 1-5.

23. Otto CM, Drobatz KJ, Soter C. Endotoxemia and tumor necrosis factor activity in dogs with naturally occurring parvoviral enteritis. 
Prevalence of canine parvovirus infection in South Eastern region, Nigeria

Journal Veterinary Internal Medicine. 1997; 11(2):65-70

24. Prittie J. Canine parvoviral enteritis: a review of diagnosis, management, and prevention. Journal of Veterinary Emerging Critical Care. 2004; 13, 167-176.

25. Shima FK, Apaa TT, Mosugu JIT. Epidemiology of canine parvovirus enteritis among hospitalized dogs in Effurun/Warri metropolitan region of Delta State, Nigeria. Open Access Library Journal. 2015; 3:120815 .
26. Smith-Carr S, Macintire DK, Swango LJ. Canine Parvovirus Part I: Pathogenesis and Vaccination. Compendium Continuing Education Practicing Veterinary, 1997; 19 (2): 125- 133

27. Sykes J E. Canine parvovirus infections and other viral enteritides. In: Sykes JE, editor. Canine and Feline Infectious Diseases. 1st ed. St Louis, MO: Elsevier; 2014; 141-15.

28. Truyen U. Evolution of canine parvovirus: a need for new vaccines? Veterinary Microbiology. 2006; 117:9-13. 